\title{
A educação popular na área da Saúde
}

\author{
People education in the Health area
}

\author{
Carlos Rodrigues Brandão ${ }^{1}$
}

Desde algum momento entre os últimos anos da década de sessenta ("a década que não acabou", segundo alguns) até os bem entrados anos setenta, a expressão: "estou realizando um trabalho de Educação Popular na área da Saúde" tornou-se corriqueira. E ela sugere um pensar a respeito de quando e como a associação entre uma coisa e a outra começou a ser realizada entre nós. Eymard Mourão Vasconcelos consegue fazer isto em pouca páginas.

Alguns anos antes, na aurora dos anos sessenta, as experiências pioneiras em idéias e práticas que têm no nome do educador Paulo Freire uma espécie de eixo de referência, não eram identificadas pelo nome de Educação Popular. Paulo Freire mesmo usava nomes como educação liberadora, educação libertadora. Um amplo projeto polissêmico abarcava uma primeira frágil safra de experiências reunidas ao redor do nome cultura popular. As associações que então se reconheciam envolvidas com tal proposta constituíam centros ou movimentos de cultura popular.

A cultura começava a ser, então, pensada como um momento do processo político, em sua dimensão subjetiva (no interior do imaginário da pessoa) $e$ objetiva (em sua realidade social, ao longo da história humana e no interior da vida cotidiana de uma comunidade). Havia um fundamento partilhado com diferenças de ideologias entre as pessoas e os movimentos participantes "da cultura popular" dos anos sessenta: a cultura se constrói na história. Ela é uma obra humana e resulta de interações mediatizadas entre o trabalho e a comunicação das consciências. Um outro suposto o completava: em sociedades desiguais, regidas por interesse e conflitos de/entre classes sociais, culturas humanas são construções de práticas da vida, de regras $e$ códigos de relações e de sistemas de sentidos que obedecem a tais interesses e procuram tornar ocultos ou desvelam as origens sociais das desigualdades $e$ as razões ideológicas e políticas dos conflitos.

Daí porque fazia sentido falar-se, então, em uma "cultura alienada". Uma cultura que seria o espelho $e$ a realização simbólica da condição social de toda uma sociedade desigual e, mais ainda, a de uma de suas classes, a dos "subalternos", dos "oprimidos", dos "trabalhadores", do "povo", da "massa

1 Professor do Departamento de Antropologia, Instituto de Filosofia e Ciências Humanas, Universidade Estadual de Campinas/ Unicamp. 
popular", nos dizeres de então. O seu equivalente individualizado seria uma "consciência alienada". Modos e processos de significação da realidade que não traduziam para seus sujeitos - individuais ou coletivos - a face politicamente verdadeira desse real pensado e vivido.

Ora, se uma cultura pode ser psicológica e socialmente dada a conhecer por meio de sua face falsa, enganadora do real e, portanto, alienada, um trabalho cultural de teor político pode ser proposto à contra-corrente da ordem dos bens, dos interesses e dos serviços, dos poderes e dos símbolos dos "opressores" e de seus emissários. Por meio de processos intencionais e ordenados de uma educação liberadora (de pessoas e de culturas), de uma alfabetização concientizadora, de uma "arte popular" (não da do "próprio povo" mas uma arte crítica a ele dirigida) seria possível criar com o povo, por uma "pedagogia do oprimido", uma nova cultura. Uma cultura enfim verdadeiramente popular, crítica, "desalienada" ... "revolucionária".

Tais os termos das propostas mais amplas dos tempos em que a Educação Popular ressurgia entre nós. Buscando então raízes culturais populares a serem de alguma maneira acrescentadas a trabalhos de arte-para-o-povo ou de alfabetização conscientizadora, volta e meia se chegava à "medicina popular". Mas eram ainda inexistentes ou muito raras as atividades de "saúde popular". De algo semelhante à educação, estendido a pessoas e a comunidades populares como um trabalho "da área da saúde". O Movimento de Educação de Base, um dos movimentos de cultura popular com atuação em boa parte do território nacional, envolveu em seu programa de "educação de base", noções de "saúde popular". Por volta de 1964 uma pequena cartilha, "mutirão para a saúde", com bonitos desenhos do Ziraldo e em forma de versos dos romanceiros nordestinos, foi distribuída em larga escala.

Ora, o teor mais visivelmente político, a vocação entre transformadora $e$ revolucionária dos programas de educação popular, ou daqueles aos quais uma experiência de educação popular aderia, são, razoavelmente bem conhecidos de todos nós. Eles podem ser encontrados, em seus rostos originais, na bela coletânea de documentos da época, coligidos por Osmar Fávero em Cultura Popular e Educação Popular - memória dos anos 60 (Graal, 1983, Rio de Janeiro). Eles foram bastante bem (e polemicamente) discutidos em livros como Educação Popular e Educação de Adultos, de Vanilda Paiva (Loyola, 1973, São Paulo).

Mas existe um outro fator fecundante de tudo o que ocorreu no interior

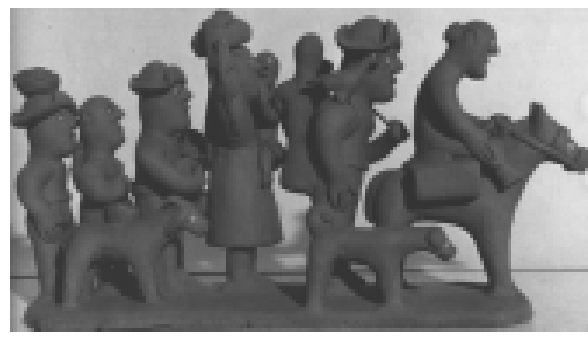


de Peuple et Culture como uma das inspiradoras do Movimento de Educação de Base. Pois a face cotidiana e concretamente pedagógica da Educação Popular nasceu e se desenvolveu em diálogo com novas teorias e práticas de um "ouvir o outro" para educá-lo - e para educar-se com ele, lembraria Paulo Freire. E o próprio "círculo de cultura" do "método Paulo Freire" é bem um seu retrato fiel.

Se a proposta básica dos movimentos de cultura popular é a realização de uma "educação conscientizadora" a ser obtida pelo crescimento interior do educando popular que por conta própria $e$ auxiliado por um educadorfacilitador aprende, ao mesmo tempo, a ler palavras, a ler-se a si mesmo e a ler seu mundo, como torná-la efetiva? Como substituir a "educação bancária” de que falava Paulo Freire por uma educação igualitária $e$ dialógica?

É este o momento em que entram em cena idéias, propostas e métodos de trabalho com pessoas e com grupos, vindos da Europa e dos Estados Unidos. Seus círculos de origem são variados. Algo pode provir da terapia $e$ do ensino centrado no cliente ou no aluno, que nos evoca Carl Rogers. Propostas chegadas à educação em que o que importa deixa de ser o saber acumulado no professor-que-ensina e que deve ser "passado" aos seus alunos de uma maneira verticalizada e pré-estruturada, para vir a ser um saber que se constrói a partir e pelo que todos e cada um dos participantes de uma comunidade aprendente podem trocar uns com os outros.

Algo pode provir das experiências norte-americanas e européias de dinâmica de grupos, introduzidas no Brasil desde o final dos anos cincoenta. Volto ao exemplo do Movimento de Educação de Base (MEB), que é o de minha experiência pessoal. Ele se inicia com a presença de um recémespecialista em dinâmica de grupos. Teorias e práticas são aprendidas e são incorporadas. Das reuniões da "equipe nacional de coordenação" ao trabalho proposto nas "escolas radiofônicas" de Educação Popular, a reunião à volta da mesa, o círculo de pessoas e de pontos de vista, o respeito ao pensamento do outro, a busca de consensos, o "crescimento por meio da troca" tornamse a rotina de cada dia.

Entre a experiência pioneira de Angicos conduzida por Paulo Freire e sua primeira equipe de educadores, e as do MEB, entre ele e outras tantas experiências de Educação Popular dos anos sessenta e das duas décadas posteriores, estas posturas figuradas no círculo e no debate, esta transformação da sala hierárquica no espaço das trocas, serão a matéria visível de propostas de uma "educação de compromisso popular". Uma múltipla aventura da educação em que o diálogo - a sempre difícil $e$ inalcançável busca do diálogo - deixa de ser uma simples metodologia de trabalho didático, para vir a se constituir como o fim e o sentido de uma educação conscientizadora.

Uma das mais criativas contribuições de algumas dentre as polissêmicas experiências de Educação Popular dos anos sessenta em diante, e do Brasil até círculos mais amplos da América Latina e, depois, de outros continentes de Terceiro Mundo, foi justamente esta mudança ideológica e pedagógica das propostas originais de ensino-centrado-no-aluno e de dinâmica de grupo trazidas ao Brasil desde o Primeiro Mundo. Talvez por uma primeira vez 
algo tão relevante é criado entre nossos educadores e, depois, exportado a todo o Mundo.

Atitudes metodológicas antes pensadas para o contexto terapêutico e pedagógico de ambientes tão distanciados de uma comunidade popular do Nordeste do Brasil, são revisitadas. São recriadas e transformadas em "armas pedagógicas" de franco valor de crescimento de posturas críticas e de motivações a uma participação popular. Não se tratava apenas de uma adaptação, pois algo bem mais do que isto foi na verdade realizado de uma maneira consistente e diversificada. Toda uma proposta de partilha por meio da educação foi então desenvolvida e posta em prática. Que fecundos e que difíceis caminhos ela, em seus múltiplos rostos, teria percorrido se o Golpe Militar de 1964 não os tivesse cortado de uma maneira tão radical e tão violenta? Anos mais tarde a pesquisa participante estenderia tais propostas a outros e aos mesmos campos.

Uma outra "descoberta" posta em prática sobretudo na aurora dos anos setenta, foi a de uma dimensão propriamente dialógica e francamente educativa em qualquer campo ou dimensão de práticas sociais. E sobretudo naquelas realizadas pelo difícil e fértil encontro entre agentes culturais eruditos e profissionalizados $e$ as pessoas e os grupos humanos populares.

Este é o momento em que com propriedade Eymard Mourão Vasconcelos pode lembrar o seguinte: "a participação de profissionais de saúde nas experiências de Educação Popular, a partir dos anos setenta, trouxe para o setor Saúde uma cultura de relação com as classes populares que representou uma ruptura com a tradição autoritária e normatizadora da Educação em Saúde" (p.130, grifo meu). De fato, com o renascimento dos programas de Educação Popular nos anos setenta, há uma diferenciação notável de ideários e de procedimentos. Agora são os próprios movimentos sociais populares, no campo e na cidade, que convocam os educadores populares (médicos, enfermeiros, assistentes sociais, artistas, cientistas sociais e outros, entre eles) a um trabalho fundado ainda nos velhos princípios da Educação Popular, mas com rostos e roupagens novos.

Este é o momento em que se pode, bem mais do que nos anos sessenta, falar de uma "experiência de Educação Popular na área da saúde". E ela se realiza quando o trabalho profissional de Saúde Pública funde-se em um trabalho cultural de Educação Popular por meio da Saúde. Quando a ação médica e a de outros profissionais da "área da Saúde" não se limita a uma assistência a clientes do povo. Quando ela se estende a uma ação cultural ampliada de diálogo e de crescimento de parte a parte, em busca de saídas e de soluções sociais a partir do que se vive e do que se troca, do que se aprende e do que se motiva, quando se dialoga crítica e criativamente sobre a vida $e$ o mundo por intermédio do corpo e da saúde. 